\title{
Adherence to medications among Nepali hypertensive population: A hospital-based cross-sectional study
}

\author{
Bhavana Shrestha, Zannatul Ferdoush, Fazle Rabbi and Ahmed Hossain* \\ Department of Public Health, North South University, Dhaka, Bangladesh
}

\begin{abstract}
Background: Hypertension is a chronic medical condition, which needs an adequate management. The patients' adherence with a proper medication of hypertension is the key factor to control hypertension and to reduce the associated complications. However, poor adherence to the antihypertensive drugs is a worldwide problem, which is responsible for adverse health outcomes and thus, increases different health complexities along with health management costs. Here we aim to identify the associated factors of medication adherence among the hypertensive patients in Nepal.

Methods: We conducted a hospital-based cross-sectional study in Nepal from September 2016 to November 2016 . We collected data of 260 hypertensive patients who are in medication of hypertension for at least 1 year. Data was collected by interview method and the medication adherence was measured by the three questions that were developed following the Morisky-Green test (MG) and Wong et al.

Results: Good adherence with medication was observed in $51.9 \%$ of the 260 -hypertensive patients. Female patients (57\%) were found to be more likely to adhere to their medication regime, compared to their male counterparts (47\%). Multivariate logistic regression indicates that married patients were twice as likely (95\% CI: $1.01-4.46 ; P<0.05)$ to adhere, compared to single or divorced patients. It also appeared that the patients who were taking medication for more than 10 years are $54 \%$ less likely to be compliant compared to the hypertensive patients who were on medication less than 10 years (OR=0.46). Availability of the antihypertensive drugs near the house (within $1 \mathrm{~km}$ ) is important to reduce the poor adherence (OR=3.10, CI: 1.68-5.87).
\end{abstract}

Conclusion: Adherence levels were higher in married hypertensive patients who are having medication for less than 10 years. Availability of the hypertensive medication near the house $(<1 \mathrm{~km})$ is also important to reduce the non-adherence on hypertensive medication.

\section{Introduction}

Control of blood pressure is a continuous approach to prevent the occurrence of any adverse health outcomes like coronary heart disease, heart failure, stroke and premature death [1]. Though safe and effective drugs are available, the management of hypertension is still far from optimal which is mostly reasoned for the poor medication adherence [2]. Medication adherence can be characterized as how much the patient complies with the medication, dietary and behavioral changes. Poor adherence is especially common among the hypertensive patients. Existing research shows that in several European countries less than 60 $\%$ of treated hypertensive subjects have an adherence to their treatment over $80 \%[3,4]$. In surveys, poor-adherence was also found $53.4 \%$ in Malaysia [2] and 41\% in Bangladesh among the hypertensive patients [5].

Patients' adherence to the prescribed antihypertensive medication is an important factor in achieving blood pressure targets. No matter how efficaciously the clinician communicates the benefits of antihypertensive therapy, patients are responsible for taking their medications. Poor adherence to antihypertensive medication is likely to be a major contributor to medication failure, which may result in more visits to healthcare professionals, additional medication switches, dose escalations, and even hospitalization [6,7]. It is estimated that approximately $50 \%$ of patients in a general hypertensive population do not take their antihypertensive medication as prescribed $[8,9]$. Therefore, improving adherence to prescribed drug regimens in this population remains a major challenge to the treating physician.

Non-communicable diseases are sweeping with an increasing trend in Nepal and hypertension is one of the most prevalent non- communicable diseases [10]. Till now, we have not found any study has been conducted to identify the associated factors of non-adherence with the anti-hypertensive medication in Nepal. But numerous epidemiological and prospective studies were conducted in different countries, which have demonstrated that hypertension which remains untreated for many years or is unsuccessfully treated for reasons such as poor adherence and adherence of the patient may lead to severe health problems like stroke, cognitive impairment etc. Therefore, it is important to find the factors associated with the poor-adherence in anti-hypertensive medication. The study will help to take necessary steps to the management of hypertension with the method of the medication.

\section{Methods}

\section{The data}

The study was a hospital-based cross-sectional survey, and we collected data from the Kathmandu University Dhulikhel Hospital of Nepal, which is located $30 \mathrm{~km}$ away from Kathmandu Valley (Capital

${ }^{\star}$ Correspondence to: Ahmed Hossain, Department of Public Health, North South University, Dhaka, Bangladesh, Tel: + (880) 172-937-8236, Fax: + (8802) 5566-8202; E-mail: ahmed.hossain@utoronto.ca

Key words: medication adherence, hypertension, cross-sectional study, Nepal

Received: February 13, 2018; Accepted: February 24, 2018; Published: February 28,2018 
city of Nepal). From the history of patient's profile, we found 260 hypertensive patients, who were suffering for at least six months, and were prescribed for medications to control hypertension. All the participants gave their informed consent to participate in the study and were informed of their right to withdraw from it at any time.

\section{Adherence with medication}

Wong et al. portrayed that the medication consistency when medical or health advice corresponds with the individual's conduct as the utilization of medication prescribed changes in the way of life, and participation in therapeutic arrangements [11]. The Morisky et al. described the treatment compliance as far as four things coded as "yes" or "no" [12]. These things identify with not taking medications because of carelessness, forgetfulness, feeling better, or feeling worse. Morisky et al. [12] emphasized on forgetting taking medication to define the medication adherence, which can be improved by a reminder from family members. We measured the adherence by asking three questions in a self-reported adherence test following the Morisky-Green test (MG) and Wong et al. Hossain and Mithila also included these three questions in their study [5]. The three questions include: (1) whether the patient continues with the medicine, (2) whether the patient continues with regular clinic attendance, and (3) whether the patient get social support from family members or friends who were concerned about the respondent's hypertension or who were helpful in reminding the respondent about taking medication $[11,12]$. The first question on medication adherence is categorized as: "adherence: yes" (where the respondent 'never misses' or 'rarely misses' to take his/her medication doses); and "adherence: no" (where the respondent 'regularly' or 'fairly regularly' misses to take his/her medication). All the questions counted as score 1 . Among these three queries, we defined the adherence with medication as "yes" if an individual is found with a total score of two including a positive response to the first question.

\section{Independent variables}

A semi-structured questionnaire was designed to obtain patient's information on sex, age, height, weight, schooling, marital status, occupation (day-labor, employed, unemployed), number of family members $(\leq 4,>4)$, average monthly family income $(<50000$ Nepalese rupee or $\geq 50000$ ), living house (own or rent), living area (urban or rural). Questions on other health related problems (yes or no), family history of hypertension (yes or no), duration of hypertension, smoking habit (yes or no), duration of high blood pressure, number of antihypertensive drugs, exercise habit, average daily sleep duration and availability of drugs near to house (within $1 \mathrm{~km}$ ) were also included. Age was calculated in years from the date of births, and body mass index (BMI) was calculated from the height and weight. The BMI was categorized as normal (BMI: 18.5-24.9), overweight (BMI: 25-29.9) and obese (BMI $\geq 30$ ). The duration of anti-hypertensive medication was categorized as $\leq 1$ years, $2-3$ years and $\geq 4$ years. Sleep duration was assessed by the question, "How many hours each day do you spend sleeping?" Sleep duration was categorized as short sleep duration $(<6$ h) and normal sleep duration ( $\geq 6 \mathrm{~h}$ ).

\section{Statistical analysis}

We analyzed the data using software R. Descriptive statistics were calculated for all of the variables, including continuous variables (presented as boxplots) and categorical variables (presented as frequencies). We did the chi-square test to evaluate the unadjusted association between each of categorical variables and medication adherence. Multivariate logistic regression analysis was conducted to get the odds ratios of factors with medication adherence. The results were reported by odds ratios (ORs) and corresponded $95 \%$ confidence intervals (CIs). P-values less than 0.05 were considered statistically significant.

\section{Ethical approval}

Ethical approval for the study protocol was obtained from the North South University Review Committee, Dhaka (NSU-PBH-EA-1032) and Institutional Review Committee of Kathmandu University School of Medical Sciences, Dhulikhel Hospital and written informed consents were obtained from all the participants.

\section{Results}

Among 260 hypertensive patients, there were 132 male and 128 female patients included in the study. The baseline characteristics of the participants, such as sex, age, marital status, schooling, occupation, average monthly income, living area, smoking history, alcohol consumption, duration of anti-hypertensive medication, presence of other chronic complications, number of drugs used for hypertension, duration of sleep, exercise, availability of hypertensive drugs near to house are described in Table 1. It appears that female (57\%) had higher prevalence of adherence with medication compared to male (47\%), though the difference is not significant at 5\% significance level. The patients who live in rented house and who belong to the poor family monthly income group (less than 50000 Nepalese rupee) are found more compliant with the antihypertensive medication. Besides, the patients who were above 60 years of age are more noncompliant compared to the patients who were in less than 50 years and 50 to 59 years old age groups (Table 2).

We fit a multivariable logistic regression model with medication adherence levels after adjusting all the factors. The adjusted odds ratios (ORs) including the confidence intervals are given in Table 2. It appears that male patients are $40 \%$ less likely to be adherent to the antihypertensive medication compared to the female group $(\mathrm{OR}=0.60$, $\mathrm{CI}=0.33-1.10)$. In addition, we found married patients were twice more likely to be adherent compared to the divorced or widowed patients $(\mathrm{OR}=2.09, \mathrm{CI}=1.01-4.46)$. The $\mathrm{p}$-value of marital status is found to be 0.05 , which indicates it is a significant variable at $5 \%$ significance level. It appears that employed patients had poor adherence to the anti-hypertensive medication compared to the unemployed patients $(\mathrm{OR}=1.96, \mathrm{CI}=0.80-4.90)$. It is to remember that most unemployed patients were housewives and therefore most housewives were less likely to take antihypertensive medications. The patients, who were living in the rent house were 2.60 times more likely to have adherence with medication compared to the patients who lived in own house $(\mathrm{OR}=$ $2.60, \mathrm{CI}=1.11-6.34)$. The patients who were having the antihypertensive medication more than 10 years were $54 \%$ less likely to have adherence compared to the new patients of $1-5$ years $(\mathrm{OR}=0.46, \mathrm{CI}=0.18-1.11)$. It also appears that the availability of the antihypertensive medication with $1 \mathrm{~km}$ is important for the patients. The patients who had the drugstore near the house (within $1 \mathrm{~km}$ ) were 3.10 times more likely to have good adherence with the medications $(\mathrm{OR}=3.10, \mathrm{CI}=1.68-5.87)$.

\section{Discussion}

Medication adherence is an important characteristic for hypertensive patients to control the blood pressure. This study found a very high percentage of poor adherence (52\%) among the Nepalese hypertensive patients. This means that for many hypertensive patients, medication adherence needs to be improved. This result is close to what 
Table 1. Participant characteristics by medication adherence and unadjusted analysis.

\begin{tabular}{|c|c|c|c|c|c|}
\hline \multirow{2}{*}{ Variables } & \multirow{2}{*}{ Categories } & \multicolumn{2}{|c|}{ Adherence Level } & \multirow{2}{*}{$\chi^{2}$ Value } & \multirow{2}{*}{ p-value } \\
\hline & & No & Yes & & \\
\hline \multirow{2}{*}{ Sex } & $\mathrm{F}$ & 55 & $73(57 \%)$ & \multirow{2}{*}{2.247} & \multirow{2}{*}{0.133} \\
\hline & M & 70 & $62(47 \%)$ & & \\
\hline \multirow{3}{*}{ Age } & $<50$ & 30 & $40(57 \%)$ & \multirow{3}{*}{3.715} & \multirow{3}{*}{0.156} \\
\hline & $50-59$ & 32 & $43(57 \%)$ & & \\
\hline & $60+$ & 63 & $52(45 \%)$ & & \\
\hline \multirow{3}{*}{ BMI } & Normal & 63 & $72(53 \%)$ & \multirow{3}{*}{1.934} & \multirow{3}{*}{0.38} \\
\hline & Overweight & 44 & $51(54 \%)$ & & \\
\hline & Obese & 18 & $12(40 \%)$ & & \\
\hline \multirow{2}{*}{ Marital Status } & Divorced/ Widowed & 30 & $21(51 \%)$ & \multirow{2}{*}{2.424} & \multirow{2}{*}{0.119} \\
\hline & Married & 95 & $114(55 \%)$ & & \\
\hline \multirow{2}{*}{ Schooling } & $\leq 5$ Years & 51 & $53(51 \%)$ & 0.016 & 0.899 \\
\hline & $5+$ Years & 74 & $82(53 \%)$ & & \\
\hline \multirow{3}{*}{ Occupation } & Day Labor & 46 & $62(57 \%)$ & \multirow{3}{*}{4.528} & \multirow{3}{*}{0.103} \\
\hline & Employed & 47 & $52(53 \%)$ & & \\
\hline & Unemployed & 32 & $21(40 \%)$ & & \\
\hline \multirow{2}{*}{ Monthly Income } & $<50000$ rupee & 92 & $105(53 \%)$ & \multirow{2}{*}{0.41} & \multirow{2}{*}{0.521} \\
\hline & $\geq 50000$ rupees & 33 & $30(48 \%)$ & & \\
\hline \multirow{2}{*}{ Living House } & Own & 112 & $107(49 \%)$ & \multirow{2}{*}{4.475} & \multirow{2}{*}{0.034} \\
\hline & Rent & 13 & $28(68 \%)$ & & \\
\hline Living Area & Rural & 49 & $56(53 \%)$ & 0.061 & 0804 \\
\hline & Urban & 76 & $79(51 \%)$ & & \\
\hline Current Smoking Status & No & 64 & $76(54 \%)$ & 0488 & 0484 \\
\hline 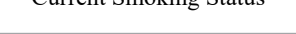 & Yes & 61 & $59(49 \%)$ & 0.400 & 0.404 \\
\hline Current Alcohol & No & 74 & $84(53 \%)$ & 013805 & 071 \\
\hline Consumption & Yes & 51 & $51(50 \%)$ & 0.15000 & 0.11 \\
\hline & 5-Jan & 25 & $36(59 \%)$ & & \\
\hline Duration of Medication & 10-Jun & 48 & $60(56 \%)$ & 4.796 & 0.09 \\
\hline & $\geq 11$ & 52 & $38(42 \%)$ & & \\
\hline Other Chronic Complications & No & 50 & $60(55 \%)$ & 0757 & 0.684 \\
\hline Uther Cnronic Compications & Yes & 75 & $75(50 \%)$ & 0.151 & 0.084 \\
\hline No of Druos/dav & 2-Jan & 45 & $53(54 \%)$ & 0172 & 0.679 \\
\hline 1NO. Or Diugs/ Gay & $2+$ & 80 & $82(51 \%)$ & $0.1 / 2$ & 0.019 \\
\hline Sleen Hour & Normal & 93 & $102(52 \%)$ & 0005 & 0.942 \\
\hline & Short & 32 & $33(50 \%)$ & & \\
\hline Availability of drugs near & No & 50 & $27(35 \%)$ & 1151 & $<0001$ \\
\hline house $(<1 \mathrm{~km})$ & Yes & 75 & $108(59 \%)$ & 11.51 & $<0.001$ \\
\hline
\end{tabular}

Table 2. Adjusted relationships between covariates and medication adherence that is analyzed using multivariate logistic regression. OR odds ratio: LCL $95 \%$ lower confidence limit of OR; UCL $95 \%$ upper confidence limit of OR.

\begin{tabular}{|c|c|c|c|c|c|c|}
\hline Variables & References & Estimate & OR & LCL & UCL & p-value \\
\hline Sex- Male & Female & -0.508 & 0.6 & 0.33 & 1.1 & 0.099 \\
\hline Age 50-59 & $<50$ & 0.404 & 1.5 & 0.7 & 3.25 & 0.301 \\
\hline Age $60+$ & $<50$ & 0.14 & 1.15 & 0.5 & 2.62 & 0.737 \\
\hline BMI - Overweight & Normal & -0.097 & 1.1 & 0.6 & 2.03 & 0.754 \\
\hline BMI - Obese & Normal & -0.676 & 0.51 & 0.19 & 1.3 & 0.164 \\
\hline Marital Status- Married & Divorced/ Widowed & 0.738 & 2.09 & 1.01 & 4.46 & 0.05 \\
\hline Schooling- $>5$ years & $\leq 5$ Years & -0.289 & 0.75 & 0.39 & 1.44 & 0.386 \\
\hline Occupation - Employed & Unemployed & -0.673 & 1.96 & 0.8 & 4.9 & 0.144 \\
\hline Occupation - Day Labor & Unemployed & 1.148 & 3.15 & 1.33 & 7.75 & 0.01 \\
\hline Monthly Income $>=50000$ & $<50000$ & -0.284 & 0.75 & 0.38 & 1.46 & 0.479 \\
\hline Living House-Rent & Own & 0.955 & 2.6 & 1.11 & 6.34 & 0.031 \\
\hline Living Area - Urban & Rural & -0.284 & 0.76 & 0.38 & 1.47 & 0.406 \\
\hline Current Smoking - Yes & No & -0.154 & 0.86 & 0.46 & 1.58 & 0.621 \\
\hline Alcohol Consumption - Yes & No & 0.054 & 1.06 & 0.58 & 1.94 & 0.859 \\
\hline Duration of Medication- 6-10 Years & 5-Jan & -0.413 & 0.66 & 0.31 & 1.39 & 0.281 \\
\hline Duration of Medication- $10+$ Years & 5-Jan & -0.786 & 0.46 & 0.18 & 1.11 & 0.087 \\
\hline Other Chronic Complications- Yes & No & -0.139 & 0.87 & 0.39 & 1.93 & 0.731 \\
\hline No. of Drugs/ day - 1-2 & $2+$ & -0.113 & 0.89 & 0.4 & 1.98 & 0.78 \\
\hline Sleep Hour - Short & Normal & 0.053 & 1.05 & 0.55 & 2.04 & 0.872 \\
\hline Availability of drugs near house $-(<1 \mathrm{~km})$ & $(\geq 1 \mathrm{~km})$ & 1.132 & 3.1 & 1.68 & 5.87 & $<0.001$ \\
\hline
\end{tabular}


has been reported from Malaysia (53.4\%) [2], Taiwan (47.5\%) [13] and Bangladesh (41\%) [5].

In this study, divorced or widowed patients who were living in an owned house, having the antihypertensive medications for more than 10 years and the availably of the drugs was not within $1 \mathrm{~km}$ have a statistically significant association with poor adherence of medication $(\mathrm{P}<0.05)$ in multivariate logistic regression. The marital status was also found as an associated factor from the study in Bangladesh [5]. We didn't find age as a significant variable but the odds ratio suggests that the patients with the age-group between 50 and 59 years are 1.50 times more likely to have good adherence with the medication compared to the younger age group ( $<50$ Years). The results are found consistent from the study in United Kingdom [15]. It appears that patients have good adherence, as the patients get older.

It can be noticed that poor adherence was not influenced by sex or by the schooling. But it appeared that male patients had poor adherence compared to the female patients. We have not found any behavioral factors that have any association with the poor adherence of the antihypertensive medications. It was also demonstrated in this study that availability of the antihypertensive medications is important to reduce the prevalence of poor adherence.

\section{Conclusion}

More than half of the hypertensive patients were found to have poor adherence, which negatively affect blood pressure control. This means that for many hypertensive patients, medication adherence needs to be improved. Developing intervention programs to address some of the factors identified is necessary to improve adherence and, in turn, to improve blood pressure control. These findings may be used to identify the subset of population at risk of poor adherence who should be targeted for interventions to achieve better blood pressure control and hence prevent complications.

\section{Competing interests}

The authors declare that they do not have any conflict of interest. The North South University has played the vital role in the design of this study, analysis, and interpretation of data and writing the manuscript.

\section{Authors' contributions}

VS participated in study conception, design and data collection. ZF and FR reviewed the manuscript and helped to draft the manuscript. $\mathrm{AH}$ contributed in study conception, design, performed statistical analysis and draft the manuscript. All authors approved of the final manuscript.

\section{Acknowledgements}

All the authors acknowledge Dhulikhal Hospital and all the participants for providing information to conduct the study.

\section{References}

1. http://www.who.int/cardiovascular_diseases/guidelines/Full\%20text.pdf

2. Ramli A, Ahmad NS, Paraidathathu T (2012) Medication adherence among hypertensive patients of primary health clinics in Malaysia. Patient Prefer Adherence. 6: 613-622. [Crossref]

3. Degli Esposti L, Saragoni S, Benemei S, Batacchi P, Geppetti P, et al. (2011) Adherence to anti-hypertensive medications and health outcomes among newly treated hypertensive patients. Clinicoecon Outcomes Res 3: 47-54. [Crossref]

4. Breitscheidel L, Ehlken B, Kostev K, Oberdiek MS, Sandberg A, et al. (2012) Reallife treatment patterns, compliance, persistence, and medication costs in patients with hypertension in Germany. J Med Econ 15: 155-165. [Crossref]

5. Hossain A, Mithila O (2016) Sleep duration and treatment compliance: A populationbased cross-sectional study of hypertensive patients in Bangladesh. BMC Research Notes 9: 271 .

6. Vrijens B, Antoniou S, Burnier M, de la Sierra A, Volpe M (2017) Current Situation of Medication Adherence in Hypertension. Front Pharmacol 8: 100. [Crossref]

7. Mekonnen HS, Gebrie MH, Eyasu KH, Gelagay AA (2017) Drug adherence for antihypertensive medications and its determinants among adult hypertensive patients attending in chronic clinics of referral hospitals in Northwest Ethiopia. BMC Pharmacol Toxicol 18: 27. [Crossref]

8. Abegaz TM, Shehab A, Gebreyohannes EA, Bhagavathula AS, Elnour AA (2017) Nonadherence to antihypertensive drugs: A systematic review and meta-analysis. Medicine (Baltimore) 96: e5641. [Crossref]

9. Lee GK, Wang HH, Liu KQ, Cheung Y, Morisky DE, et al. (2013) Determinants of medication adherence to antihypertensive medications among a Chinese population using Morisky Medication Adherence Scale. PLoS One 8: e62775. [Crossref]

10. Mishra SR, Neupane D, Bhandari PM, Khanal V, Kallestrup P (2015) Burgeoning burden of non-communicable diseases in Nepal: a scoping review. Global Health 11: 32. [Crossref]

11. Wong MC, Jiang JY, Griffiths SM (2010) Factors associated with antihypertensive drug compliance in 8,884 Chinese patients: a cohort study. J Epidemiol Community Health 64: 895-901. [Crossref]

12. Morisky DE, Green LW, Levine DM (1986) Concurrent and predictive validity of a self-reported measure of medication adherence. Med Care 24: 6774. [Crossref]

13. Li WW, Kuo CT, Hwang SL, Hsu HT (2012) Factors related to medication nonadherence for patients with hypertension in Taiwan. J Clin Nurs 21: 1816-1824. [Crossref]

14. Krousel-Wood M, Islam T, Webber LS, Re RN, Morisky DE, et al. (2009) New medication adherence scale versus pharmacy fill rates in hypertensive seniors. $\mathrm{Am} \mathrm{J}$ Manag Care 15: 59-66. [Crossref]

15. Maguire LK, Hughes CM, McElnay JC (2008) Exploring the impact of depressive symptoms and medication beliefs on medication adherence in hypertension-a primary care study. Patient Educ Couns 73: 371-376. [Crossref]

Copyright: (C2018 Shrestha B. This is an open-access article distributed under the terms of the Creative Commons Attribution License, which permits unrestricted use, distribution, and reproduction in any medium, provided the original author and source are credited. 